\title{
Gamascintigraphic in Vivo-in Vitro Evaluation of Floating Matrix Tablet
}

\author{
Swapnila Shinde (Vanshiv) $\mathbf{V}^{1 *}$, Joshi H $\mathbf{P}^{2}$ and Dhas S R \\ ${ }^{1}$ Department of Pharmaceutics, S.T.E.S's Sinhgad Institute of Pharmacy, Narhe, Pune 411 041, India \\ ${ }^{2}$ Manager, Dr. Reddy's Laboratory, Hyderabad 500049, India
}

\begin{abstract}
Background of the work: Gastroretentive drug delivery system can retain the dosage form in the gastric region for several hours. Prolong gastric retention helps in improving bioavailability and improves solubility of drugs that are less soluble in a high $\mathrm{pH}$ environment. For designing of GRDDS Atenolol was selected as a model drug. It has been used for the treatment of hypertension. Atenolol has short elimination half-life, stable at $\mathrm{pH} 1.2$ and as the $\mathrm{pH}$ increase, the drugs becomes unstable and thus low oral bioavailability. In order to improve its therapeutic effectiveness Atenolol is designed in the form of floating tablet formulation. Purpose: The aim of the present work was to develop hydrodynamically balanced system for atenolol, $\beta$-blocker as a single unit floating tablet. Formulation includes the use of rate controlling polymer such as Locust Bean gum (LBG) in combination of HPMC $\mathrm{K} 4 \mathrm{M}$ and gas generating agent Sodium bicarbonate. Summary and conclusion: Tablet was prepared by direct compression method and evaluated for physico-mechanical properties. The statistical method was utilized to optimize the effect of independent variables namely amount of HPMC K4M, LBG and three dependent responses such as Cumulative drug release, Floating lag time, Floating time. Graphical and mathematical analysis of the results allowed the identification and quantification of the formulation variables influencing the selected responses. To study the gastrointestinal transit of the optimized Gastroretentive formulation, the in vivo Gamascintigraphy was carried out in six healthy rabbits, after radio labeling the formulation with $99 \mathrm{mTc}$. The transit profiles demonstrated that the dosage form was retained in the stomach for more than 5 hrs. The study signifies the potential of the developed system for stomach targeted delivery of Atenolol with improved bioavailability.
\end{abstract}

Keywords: Floating tablet, factorial design, Gamascintigraphy, antihypertensive model drug, HPMC, Locust bean gum.

\section{INTRODUCTION}

Novel dosage forms have been designed to maintain relatively constant plasma drug concentration by reducing fluctuations between peak and trough drug concentration. The aim is to keep this fluctuation within the range of plasma concentration known to provide therapeutic efficacy.

In the last few decades, gastro retentive drug delivery systems have been developed extensively. The gastric floating drug delivery system offers many of benefits for the better delivery of drug which has a narrow absorption window in the upper gastrointestinal tract and exhibits poor solubility in the intes- tinal tract. For the delivery of drug which are unstable in the intestinal environment. It also enhances the action of drug that acts locally in the stomach to prolong the gastric retention time for optimal absorption. ${ }^{1}$

In the present study Atenolol is used as model drug. Atenolol is $\beta$-blocker; it has been used in hypertensive and in patients with ischemic heart disease. It is incompletely absorbed from the GI tract of human with an absorption ranging from $28 \%$ to $47 \%$, and a bioavailability of $36 \%$ of the whole dose. ${ }^{2}$ Atenolol is a weak base with good solubility in acidic $\mathrm{pH}$ but in alkaline $\mathrm{pH}$ solubility significantly reduced. Atenolol is commercially available as a
DOI: $10.5530 /$ ijper.48.3.10

Address for correspondence:

Dr. Swapnila Vivek Shinde Department of Pharmaceutics, S.T.E.S's Sinhgad Institute of Pharmacy, Narhe, Pune - 411041 , India.

Phone: +912066831816

Fax: +912066831816

E-mail: swapnila84@rediffmail.com

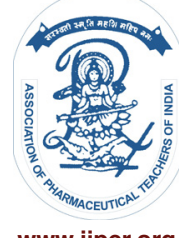

www.ijper.org 
conventional tablet. Administration of atenolol conventional tablets in $100 \mathrm{mg} /$ day doses may cause fluctuations in the plasma concentration resulting in side effects or reduction in the drug concentration at receptor site. ${ }^{3}$ It is reported that in case of oral administration of atenolol, it can induce side effects such as diarrhea, nausea, mesenteric arterial thrombosis, ischemic colitis and dry mouth. ${ }^{4}$ The short half-life of Atenolol i.e. 6 hours \& narrow absorption window make Atenolol suitable candidate for formulation of floating drug delivery system.

In the present study the efforts have been focused on the development of floating drug delivery system which will help to retain the dosage form in the stomach and to increase gastric residence time, resulting in prolonged drug delivery in stomach using gel-forming polymers.

Atenolol floating tablets was developed for the treatment of hypertension with single daily dose.

The Floating polymers used in the formulations were HPMC K4M and Locust bean gum (LBG) along with sodium bicarbonate as a low density polymer, gelling agent and gas generating agent. The optimum formula obtained that combined excellent floating behavior, with controlled drug release characteristics and shown good physical stability after storage at $40{ }^{\circ} \mathrm{C} / 75 \% \mathrm{RH}$ for 3 months. The final formulation was further investigated in six healthy rabbits to determine the gastric retention period by Gamascintigraphy technique. The objective of the present investigation was to design and evaluate gastro retentive drug delivery system with special reference to floating effervescent Atenolol Tablet.

\section{MATERIAL AND METHODS}

Atenolol was received as a gift sample from Dr. Reddy's laboratory, Hyderabad; India. HPMC K4 M (Signet chemical corporation Pune, India), Locust Bean Gum (HI media, India), Sodium bicarbonate, Magnesium stearate, Talc (Thomas Baker, Mumbai, India), Crosspovidone (Research lab fine chem. Mumbai, India) were used as excipients and obtained from the indicated sources. All other ingredients and reagents were of analytical grade and were used as received.

\section{METHODS}

\section{Preparation of Atenolol floating tablets}

$100 \mathrm{mg}$ dose of Atenolol was geometrically mixed with the required quantities of polymer blend such as hydroxypropyl methyl cellulose (HPMC K4M) as a low density hydrophilic swellable polymer\& Locust bean gum (LBG) as a gelling agent and sodium bicarbonate is used as gas generating agent by geometric mixing. The powder blend was then lubricated with magnesium stearate $(1 \%)$ and compressed on 12 station compression machine (CIPS Machinery) using single $10 \mathrm{~mm}$ flat punch. The tablet weight was not constant because that would require addition of diluent as filler; addition of this diluent may show the variation in the release profile. Thus, we do not alter the amount of diluent in the formulation to nullify any effect due to change in the proportion of diluents.

\section{Optimization by $3^{2}$ factorial designs}

A $3^{2}$ randomized factorial design was selected for the optimization of Atenolol floating tablet. The design was applied to study the effect of HPMC K4M and LBG on physicochemical characteristic of the tablet. The amount of Locust bean gum $\left(\mathrm{X}_{1}\right)$ and concentration of HPMC K4 $\mathrm{M}\left(\mathrm{X}_{2}\right)$ were selected as independent variables, in this study. These two factors were evaluated, each at three levels. The actual units of higher, middle and lower levels of factor $\mathrm{X}_{1}$ and $\mathrm{X}_{2}$ were $50 \mathrm{mg}, 75 \mathrm{mg}$, and $100 \mathrm{mg}$. The coding was $+1,0$ and -1 , respectively for higher, middle and lower levels of each factor. The dependent responses are \% cumulative release (Y1), floating lag time (Y2) and Floating time (Y3). The experimental design with corresponding formulations is outlined in Table 1.

\begin{tabular}{lcccccc}
\hline \multicolumn{7}{l}{ Table 1: Trial batches of Atenolol floating tablets } \\
\hline Ingredients & T1 & T2 & T3 & T4 & T5 & T6 \\
\hline Atenolol & 100 & 100 & 100 & 100 & 100 & 100 \\
Locust bean gum & 100 & 100 & 100 & 50 & 150 & 100 \\
HPMC K4M & 50 & 100 & 150 & 100 & 100 & 25 \\
Crospovidone & 150 & 150 & 150 & 150 & 150 & 150 \\
Sodium bicarbonate & 40 & 40 & 40 & 40 & 40 & 40 \\
Magnesium stearate & 4 & 4 & 4 & 4 & 4 & 4 \\
Talc & 4 & 4 & 4 & 4 & 4 & 4 \\
\hline
\end{tabular}

*All quantities are in $\mathrm{mg}$ 


\section{Physicochemical characterization of floating tablet}

\section{Drug content and physical evaluation}

The tablets were assayed for drug content using $0.1 \mathrm{~N}$ $\mathrm{HCl}$ as the solvent and the samples were analyzed spectrophotometrically (JASCO, V-630)at $224 \mathrm{~nm}$. The tablets were also evaluated for hardness, friability, and weight variation.

\section{The floating lag time and the total floating time}

The floating lag time and the total floating time were determined by observation of the floating behaviours in the release test using a USP type II paddle apparatus (Electro lab, India). The dissolution medium were artificial gastric fluid $(\mathrm{pH} 1.2$, simulate gastric $\mathrm{pH}$ in fasted condition) or hydrochloride acid solution $(\mathrm{pH}$ 3.0, and 5.0, simulate gastric $\mathrm{pH}$ in fed condition). ${ }^{5}$ The time interval between the introduction of the tablet into the release medium and its buoyancy to the surface was taken as floating lag time and the total floating time was observed visually. ${ }^{6}$

\section{Density measurements}

The apparent densities of the tablets were calculated, from their volumes and masses $(n=6)$. The volumes ofthe cylindrical tablets were calculated from their heights $b$ and radii $r$ (both determined with a micro meter gauge) using mathematical equation for cylinder $\left(v=\pi \times r^{2} \times h\right)$ the density of $0.1 \mathrm{~N} \mathrm{HCl}$ at $37^{\circ} \mathrm{C}$ was determined with a pycnometer $(n=3)$.

\section{Swelling ability (water uptake study)}

The swelling behaviour of the tablets was determined, in triplicate, according to the method described by Dorozynski et al. ${ }^{8}$ Briefly, a tablet was weighed (W1) and placed in a glass beaker, containing $200 \mathrm{~mL}$ of 0.1 $\mathrm{N} \mathrm{HCl}$, maintained in a water bath at $37^{\circ} \pm 0.5^{\circ} \mathrm{C}$. At regular time intervals, the tablet were removed and the excess surface liquid was carefully removed by a filter paper. The swollen tablet was then reweighed $\left(\mathrm{W}_{2}\right)$. The swelling index (SI) was calculated using the formula;

$$
\mathrm{SI}=\left(\mathrm{W}_{2}-\mathrm{W}_{1}\right) / \mathrm{W}_{1}
$$

Where, $\mathrm{W}_{2}$ - Weight of swelled tablet, W1- Initial weight of tablet.

\section{In Vitro Drug Release Study}

The in vitro drug release was performed using USP 24 type-II paddle apparatus using $900 \mathrm{~mL}$ of $0.1 \mathrm{~N} \mathrm{HCl}$ at paddle rotation of $100 \mathrm{rpm}$ at $37^{\circ} \mathrm{C} \pm 0.5^{\circ} \mathrm{C}$. The samples were withdrawn at specific time intervals $1 \mathrm{hrs}$. $2 \mathrm{hr}$ up to $8 \mathrm{hr}$. and replaced with the fresh medium. The samples were filtered through a $0.45-\mu \mathrm{m}$ membrane filter, suitably diluted, and analysed at $224 \mathrm{~nm}$ using dou- ble-beam UV/ visible spectrophotometer. Cumulative percentage drug release was calculated using the PCP Disso v 3 software (Poona College of Pharmacy, Pune, India).

\section{Kinetic modeling of drug release profiles}

The dissolution profiles of all formulae in $0.1 \mathrm{~N} \mathrm{HCl}$ were fitted to zero-order, first-order, Higuchi ${ }^{9}$ and Korsmeyer-Pappas kinetic models. ${ }^{10}$ The model with the highest correlation coefficient was considered to be the best fitting one.

\section{In vivo Gamascintigraphy study}

\section{Preparation and administration of the radio labeled tablet}

Gamma scintigraphic technique was used for investigating the In vivo gastric retention of the optimized tablet formulation (batch F 2). Tablet formulation was radio labeled with $99 \mathrm{~m}$ Tc. It was uniformly mixed with the final tablet blend and compressed using $\mathrm{KBr}$ hydraulic press at suitable pressure. Radiolabel efficiency was evaluated using thin layer chromatography. ${ }^{11}$ Instant thin layer chromatographic silica gel plates were used as a stationary phase and $100 \%$ acetone was used as mobile phase. Percent radio labeling was calculated as follows.

$\%$ Radio labelling $=\frac{\text { Radioactivity retained in the lower half of the strip }}{\text { Total count present with the strip }} \times 100$

The radiolabel tablet was administered orally via feeding tube to each rabbit without anesthesia. For the study the permission was obtained from Institutional Ethical Review Board. Six 1-year-old male albino rabbits were used to monitor the in vivo transit behavior of the floating tablet. These rabbits were divided into 2 groups (group I and group II). None of them had symptoms or a past history of gastrointestinal (GI) disease. In order to standardize the conditions of GI motility, the animals were fasted for 12 hours prior to the commencement of each experiment.

\section{In vivo Gamascintigraphy}

The location of the formulation in the stomach was monitored by keeping the subjects in front of a gamma camera a Specific stomach site (anterior) were imaged by gamma camera after definite time intervals and activity counts were recorded to calculate the counts per minute (cpm). All counts were corrected for background and isotope decay. The gamma images were recorded using an online computer system. In between the gamma scanning, the animals were freed and allowed to move and carry out normal activities but were not allowed to take any food or water until the formulation had emptied the stomach completely. ${ }^{12}$ 


\section{RESULT AND DISCUSSION}

\section{Preliminary trials}

In the preliminary trials all the tablet (Batch T1 to T6) were physically evaluated. All the formulated tablets showed percentage friability less than $1 \%$, indicating good mechanical resistance. Thickness of tablet was in the range of 6 to $8 \mathrm{~mm}$ and diameter was $10.0 \pm 0.05$ $\mathrm{mm}$. hardness of the tablet was in the range of $5-6 \mathrm{~kg} /$ $\mathrm{cm}^{2}$. The assayed content of the drug in various formulations varied between 97.85 to $101.5 \%$. All the tablet formulae showed acceptable physicochemical properties and complied with the pharmacopoeial specifications, drug content and friability.

In the preliminary trials the effect of HPMC K 4 $\mathrm{M}, \mathrm{LBG}$ alone and in combination along with sodium bicarbonate as gas generating agent was studied. Other grades of the HPMC were not considered in the formulation due to their high viscosities which may ultimately affect the release pattern. The formulation containing HPMC K4 M alone shown that at low concentration the tablet could not float more than $5 \mathrm{hrs}$ and not able to maintain physical integrity, also shown initial bursting effect, this might be due to low swelling index and low polymeric viscosity thus, the floating tablet of Atenolol was not prepared using HPMC K4 $\mathrm{M}$ alone. Therefore to improve its physical integrity locust bean gum was added in the formulation as a gelling agent due to its gelling property it could impart viscoelasticity to the tablet. The use of viscosity gum solutions strongly increases with increasing concentration of gum. This behaviour is attributable to the interaction or entanglement, increasing the effective macromolecule dimensions and molecular weight. As a result of rheology of hydrated product, the swollen particles coalesce. This result in a continuous viscoelastic matrix that fills the interstices, maintaining the integrity of tablet and retarding further penetration of the dissolution medium ultimately the limitation of initial bursting effect was overcome by controlling the release pattern.

In the preliminary trials, $5 \%$ of sodium bicarbonate was added as a gas generating agent in all formulations, which resulted in floating lag time in the range of 1 min to $4 \mathrm{~min}$. Therefore the concentration of sodium bicarbonate was varied from $10 \%$ to $20 \%$ in order to reduce the floating lag time. It was found that as the amount of sodium bicarbonate increases, the floating lag time decreases. Thus, sodium bicarbonate $15 \%$ was essential to achieve optimum invitro buoyancy, floating lag time less than 40 seconds and floating duration was more than 15 hrs. Further increase in concentration of sodium bicarbonate does not show any significant effect on floating behaviour. Moreover, the increased in the amount of sodium bicarbonate caused a large amount of effervescent, which in turned resulted in pore formation, which leads to rapid hydration of the polymer matrix and thereby to rapid drug release. Therefore, level of sodium bicarbonate was kept constant at $15 \%$ and was not considered further in the optimization as dependent variable. In the drug release profile, the drug release was in accordance with the USP specifications. According to USP test -4 the amount dissolved at 4, 8, 12 and 24 h should be $10 \%$ to $25 \%, 35$ to $60 \%, 55$ to $80 \%$ and more than $80 \%$ respectively. The formulation containing low concentration of HPMC K 4 M shown release pattern more than $90 \%$. Whereas batch T2 to T5 shown greater retardation of the high concentration of polymer.

\section{Factorial design}

Design Expert 8.0 software was used for studying effect of independent variables on responses. Experimental design layout developed for 9 possible combinations of Atenolol floating tablet formulations is shown in Table 2 .Various models such as Linear, 2FI, Quadratic and Cubic, were fitted to the data and the model which fit well was suggested by software and was tested for analysis of variance (ANOVA). Regression polynomials were calculated for the individual dependent variables and then contour plots and 3D surface graphs were obtained for each individual dependent variable. Mathematical models were generated for each dependent variable or response (R) and expressed as Eqs. (1) -(3). The main effects (X1 and X2) represent the average result of changing one factor at a time from its low to high value. The interaction terms $(\mathrm{X} 1, \mathrm{X} 2)$ show how the response changes when two factors are simultaneously Changed. The polynomial terms $\left(\mathrm{X}_{1}^{2}\right.$ and $\left.\mathrm{X}_{2}^{2}\right)$ are included to investigate nonlinearity.

\section{Characterization of Atenolol floating tablet}

All the tablet formulae showed acceptable physicochemical properties and complied with the pharmacopoeial specifications, drug content and friability. Data shown in Table 3.

\section{Swelling Index}

The hydration ability of the formula is important because it influences: (i) tablet buoyancy, (ii) floating lag time, floating time and (iii) drug release kinetics. It could be concluded that the test medium uptake of the prepared matrices depends on the type of polymer. The formula F9 showed maximum swelling indices throughout the study period. Many authors state 


\section{Table 2: Optimization batches by $3^{2}$ factorial designs}

\begin{tabular}{llllllllll} 
Ingredients & F1 & F2 & F3 & F4 & F5 & F6 & F7 & F8 & F9 \\
\hline Atenolol & 100 & 100 & 100 & 100 & 100 & 100 & 100 & 100 & 100 \\
Locust bean gum & 50 & 50 & 50 & 75 & 75 & 75 & 100 & 100 & 100 \\
HPMC K4M & 50 & 75 & 100 & 50 & 75 & 100 & 50 & 75 & 100 \\
Crospovidone & 150 & 150 & 150 & 150 & 150 & 150 & 150 & 150 & 150 \\
Sodium bicarbonate & 75 & 75 & 75 & 75 & 75 & 75 & 75 & 75 & 75 \\
Magnesium stearate & 4 & 4 & 4 & 4 & 4 & 4 & 4 & 4 & 4 \\
Talc & 4 & 4 & 4 & 4 & 4 & 4 & 4 & 4 & 4 \\
\hline
\end{tabular}

\begin{tabular}{llllll} 
Table 3: Characterization of optimized batches of Atenolol floating tablets \\
$\begin{array}{lllll}\text { Formulation } \\
\text { Code }\end{array}$ & $\begin{array}{l}\text { Floating } \\
\text { lag time } \\
\text { (Sec) }\end{array}$ & $\begin{array}{l}\text { Floating } \\
\text { duration } \\
\text { (hr) }\end{array}$ & $\begin{array}{l}\text { Density } \\
\mathbf{g} / \mathbf{c m}^{3}\end{array}$ & $\begin{array}{l}\text { Swelling } \\
\text { index (\%) }\end{array}$ & $\begin{array}{l}\text { \% } \\
\text { Cum.Drug } \\
\text { Release (8 hr) }\end{array}$ \\
\hline F1 & $22 \pm 5$ & $3 \pm 2$ & 0.6 & $79.9 \pm 2.8$ & $94.99 \pm 1.2$ \\
F2 & $27 \pm 3$ & $12 \pm 1$ & 0.89 & $120.89 \pm 3.2$ & $69.34 \pm 2.7$ \\
F3 & $38 \pm 4$ & $18 \pm 2$ & 0.85 & $110.8 \pm 2.7$ & $63.03 \pm 1.6$ \\
F4 & $35 \pm 7$ & $4 \pm 1$ & 0.98 & $74.11 \pm 1.7$ & $99.21 \pm 1.9$ \\
F5 & $52 \pm 8$ & $15 \pm 2$ & 0.89 & $112.31 \pm 1.5$ & $74.03 \pm 2.1$ \\
F6 & $58 \pm 3$ & $21 \pm 3$ & 0.82 & $139.35 \pm 2.5$ & $67.33 \pm 2.3$ \\
\hline F7 & $60 \pm 5$ & $7 \pm 2$ & 0.91 & $103.6 \pm 2.9$ & $94.16 \pm 2.6$ \\
F8 & $80 \pm 7$ & $20 \pm 3$ & 0.87 & $138.82 \pm 1.4$ & $72.1 \pm 1.8$ \\
\hline F9 & $120 \pm 6$ & $27 \pm 2$ & 0.85 & $145.79 \pm 1.9$ & $62.04 \pm 3.1$ \\
\hline
\end{tabular}

that, greater the swelling index of the polymer, slower is the release of the drug. ${ }^{13-15}$ Hence the decrease in the drug release rate may be explained due to an extensive swelling property of HPMC and LBG. So formulations containing optimum amount of swelling index was considered which in turns affected drug release rate i.e. 69\%, 27 sec. FLT and tablet could float more than 12 hours as shown in Table 3. Swelling and erosion mechanisms of HPMC matrices have been reported by Viridéna et al. ${ }^{16}$ It was assumed that swelling behaviour of these hydrophilic tablets starts with water diffusion into the glassy HPMC material where the water plasticizes the polymer and reduces its glass transition temperature, Tg. When $\mathrm{Tg}$ has decreased to ambient temperature, a transformation from a glassy state to a rubbery state occurs. As the water continues to enter the tablet, a highly concentrated polymer solution is formed, denoted as a gel layer. The solvent continues to penetrate the tablet, and the gel layer and the dimensions of the swollen tablet increase, a process normally referred to as the swelling process.

\section{Density measurement}

All the formulated tablet shown densities in the range of $0.6 \mathrm{~g} / \mathrm{cm}^{3}$ to $0.98 \mathrm{~g} / \mathrm{cm}^{3}$. This may be due to gas generated in the $0.1 \mathrm{~N} \mathrm{HCL}$ is trapped and protected within polymeric gel, formed by hydration of polymer, thus decreasing the density of tablet below $1 \mathrm{~g} / \mathrm{cm}^{3}$ and tablet becomes buoyant.

\section{Data analysis}

All responses were fitted to linear, interaction or quadratic models using Design expert software. Quadratic model was selected for percent cumulative release, floating time and factorial interaction suggested for floating lag time. 


\begin{tabular}{|c|c|c|c|c|c|c|}
\hline Source & $\begin{array}{l}\text { Sum of } \\
\text { Square }\end{array}$ & Df & $\begin{array}{l}\text { Mean } \\
\text { square }\end{array}$ & F value & $\begin{array}{l}P \text { value } \\
\text { Prob }>F\end{array}$ & Significant \\
\hline Model & 7105.6 & 3 & 2368.56 & 34.00 & 0.0009 & \\
\hline$X^{1}-$ LBG & 4988.1 & 1 & 4988.17 & 71.60 & 0.0004 & \\
\hline $\mathrm{X}_{2}$ - HPMC K4M & 1633.5 & 1 & 1633.50 & 23.45 & 0.0047 & \\
\hline$x_{1} x_{2}$ & 484.00 & 1 & 484.00 & 6.95 & 0.0462 & \\
\hline Residual & 348.33 & 5 & 69.67 & & & \\
\hline Corr. Total & 7454.0 & 8 & & & & \\
\hline
\end{tabular}

\section{Effect of formulation variables on floating lag time and floating time}

For the given response two factorial interaction models is significant, data shown in table no 4. The Model F-value of 34.00 implies the model is significant. There is only a $0.09 \%$ chance that a "Model F-Value" this large could occur due to noise. $\mathrm{P}$ value less than 0.0500 indicate model terms are significant. In this case $A, B, A B$ are significant model terms.
From the Figure 1, it was observed that there was a significant effect of polymer HPMC K4M \& LBG on the given response i.e. floating lag time.

Equation (Eq.1) for response Y1 (Floating lag time) is as follows

$\mathrm{Y}_{1}=+54.66+28.83 \mathrm{X} 1+16.50 \mathrm{X} 2+11.00 \mathrm{X}_{1} \mathrm{X}_{2}$.

Where, $\mathrm{Y}_{1}$-Floating lag time, $\mathrm{X}_{1}-$ Locust bean gum, $\mathrm{X}_{2}-\mathrm{HPMCK} 4 \mathrm{M}$

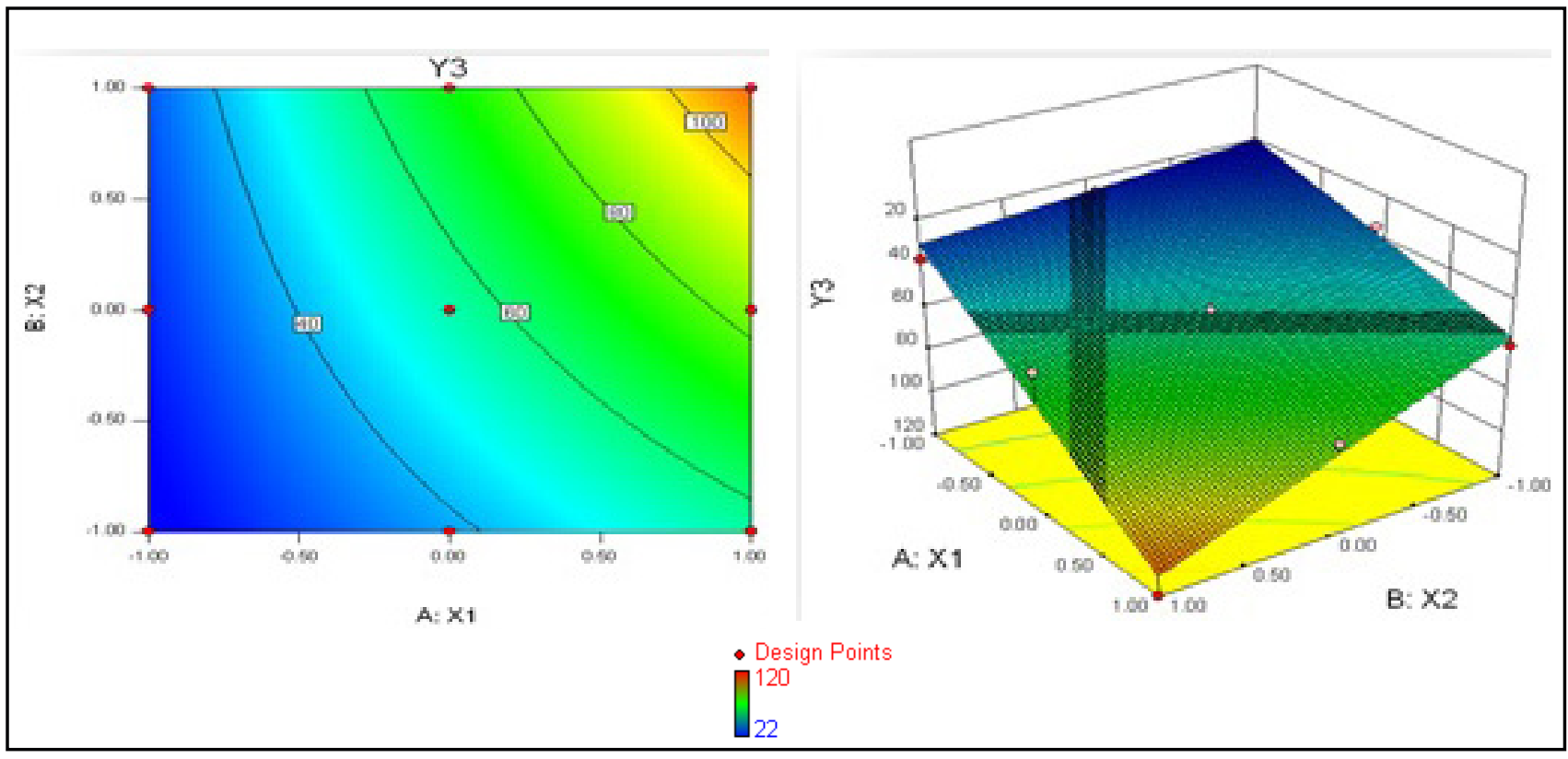

Figure 1: (a) Two dimensional contour plot; (b) three dimensional (3D) response surface plots for $Y_{3}$ (Floating Lag time in sec.)

The results of the equation indicate that there is direct effect of $\mathrm{X}_{1}$ (the concentration of LBG) \& effect of $\mathrm{X}_{2}$ (the concentration of HPMC K4M) on floating lag time. Moreover, the concentration of HPMC K4M \&LBG had a positive effect on floating time. Formulation F1 containing the lowest concentration HPMC K4M \& LBG showed the lowest floating lag time i.e. $27 \mathrm{sec}$, Formulation containing highest concentration of HPMC K4M (100 mg) and LBG (100 mg), showed highest floating lag time i.e.120 sec. These results may be due to the low viscosity and low bulk densities of HPMC K4M and LBG maintain the density less than gastric content and decreases the floating lag time.

\section{Effect of formulation variables on Floating time}

For the given response Quadratic model is significant (Table 5). The Model F-value of 379.06 implies the model is significant. There is only a $0.02 \%$ chance that 
a "Model F-Value" this large could occur due to noise. The interaction terms $\mathrm{X}_{1} \mathrm{X}_{2}$ show that their effect and interaction were statically significant of which $\mathrm{P}$ values are less than 0.0500 indicate model terms are significant. In this case $\mathrm{A}, \mathrm{B}, \mathrm{AB}, \mathrm{B}^{2}$ are significant model terms.

From the Figure 2, it was observed that there is significant effect of polymer HPMC K4M \& LBG on the given response i.e. floating time. As HPMC and LBG hydrophilic swelling polymer and gelling agent respectively. Upon contact with gastric fluid, HPMC takes up water and swell, which retarded the drug release .The increased in the volume greater than the increased in mass during swelling, the density decreases and the systems, starts to float. The investigated gastric floating systems employed $\mathrm{NaHCO}_{3}$ as a gas-forming agent dispersed in a hydro gel matrix (HPMC K 4M and LBG). This suggests that the gel layers, formed by the investigated polymers, enabled efficient entrapment of the generated gas bubbles. The possible increase in tablet porosity made it float on the test medium $(0.1 \mathrm{~N} \mathrm{HCl})$ for this extended period of time.

\begin{tabular}{|c|c|c|c|c|c|c|}
\hline Source & $\begin{array}{l}\text { Sum of } \\
\text { Square }\end{array}$ & Df & $\begin{array}{l}\text { Mean } \\
\text { square }\end{array}$ & $F$ value & $\begin{array}{l}P \text { value } \\
\text { Prob }>\text { F }\end{array}$ & Significant \\
\hline Model & 544.03 & 5 & 108.81 & 379.06 & 0.0002 & \\
\hline$X_{1}-$ LBG & 73.50 & 1 & 73.50 & 256.06 & 0.0005 & \\
\hline$X_{2}-$ HPMC K4M & 450.67 & 1 & 450.67 & 1570.0 & $<0.0001$ & \\
\hline$X_{1} X_{2}$ & 6.25 & 1 & 6.25 & 21.77 & 0.0186 & \\
\hline $\mathbf{X}_{1}{ }^{2}$ & 2.72 & 1 & 2.72 & 9.48 & 0.0542 & \\
\hline$X_{2}^{2}$ & 10.89 & 1 & 10.89 & 37.94 & 0.0086 & \\
\hline Residual & 0.86 & 3 & 0.29 & & & \\
\hline Corr total & 544.89 & 8 & & & & \\
\hline
\end{tabular}

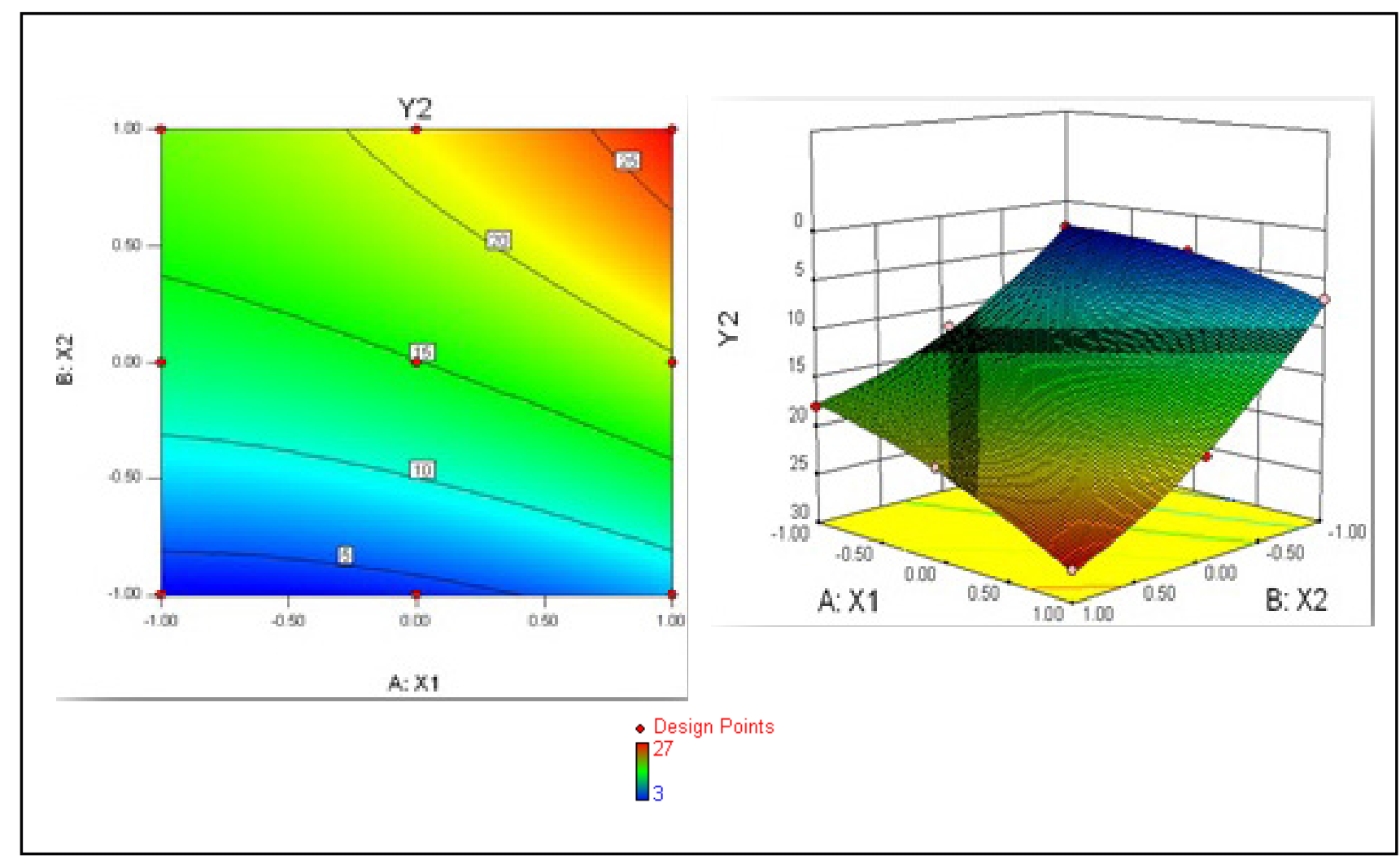

Figure 2: (a) Two dimensional contour plot; (b) three dimensional (3D) response surface plots for $\mathrm{Y}_{2}$ (Floating time in hr.) 
These matrices are fabricated so that upon arrival in the stomach, carbon dioxide gas is liberated by the acidity of the gastric contents and is entrapped in the jellified hydrocolloid. A decrease in specific gravity causes the dosage form to float on the chime. ${ }^{17}$

Equation (Eq.2) for response $\mathrm{Y}_{2}$ (Floating time) is as follows

$\mathrm{Y}_{2}=+14.88+3.50 \quad \mathrm{X}_{1}+8.66 \mathrm{X}_{2}+1.25 \mathrm{X}_{1} \mathrm{X}_{2}+1.16 \mathrm{X}_{1}^{2}{ }^{2}$ $2.33 \mathrm{X}_{2} 2$.

Where, $\mathrm{Y}_{2}$-Floating time, $\mathrm{X}_{1}$-Locust bean gum, $\mathrm{X}_{2}-$ HPMCK4M

\section{Effect of formulation variables}

For the given response Quadratic model is significant (Table 6). The Model F-value of 190.74 implies the model is significant. There is only a $0.06 \%$ chance that a "Model F-Value" this large could occur due to noise. The interaction terms $\mathrm{X}_{1} \mathrm{X}_{2}$ show that their effect and interaction were statically significant of which $\mathrm{P}$ values are less than 0.0500 indicate model terms are significant.In this case $\mathrm{A}, \mathrm{B}, \mathrm{AB}$ are significant model terms.
Equation (Eq.3) for response $Y_{3}(\%$ Cumulative release in $8 \mathrm{hr}$ ) is as follows

$\mathrm{Y}_{3}=+74.654+0.156 \mathrm{X}_{1}-15.993 \mathrm{X}_{2}-0.0400 \mathrm{X}_{1} \mathrm{X}_{2}-4.2466$ $\mathrm{X}_{1}^{2}+8.303 \mathrm{X}_{2}^{2}$

Where, $\mathrm{Y}_{3}-\%$ Cumulative release, $\mathrm{X} 1-$ Locust bean gum, $\mathrm{X}_{2}-\mathrm{HPMC}$ K4M

The results of the equation indicate that the effect of $\mathrm{X}_{2}$ (the concentration of HPMC K4M) was significant than the effect of $\mathrm{X}_{1}$ (the concentration of LBG). Moreover, the concentration of HPMC K4M had a negative effect on percent Cumulative release. Formulation F3 containing highest concentration of HPMC K4M (100 mg) and lowest concentration of LBG $(50 \mathrm{mg})$, showed lowest

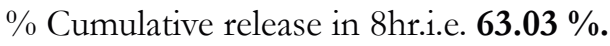

From the Figure 3, it observed that HPMC K4M having the significant effect on the response i.e. \% cumulative release. The differences in the release may be due to the amount of gel layer formed on the surface of the tablets. HPMC K4M at higher concentrations results in a greater amount of gel being formed. This gel increases diffusion length so that drug release was decreased.

\section{Table 6: ANOVA of Response $1\left(\mathrm{Y}_{1}\right)-\%$ Cumulative release}

\begin{tabular}{llllll} 
Source & Sum of Square & Df & Mean square & F value & P value Prob> F Significant \\
\hline Model & 1708.83 & 5 & 341.77 & 190.74 & 0.0006 \\
$\mathbf{X}_{\mathbf{1}}$ - LBG & 0.15 & 1 & 0.15 & 0.082 & 0.7930 \\
$\mathbf{X}_{\mathbf{2}}$-HPMC K4M & 1534.72 & 1 & 1534.72 & 856.51 & $<0.0001$ \\
$\mathbf{X}_{\mathbf{1}} \mathbf{X}_{2}$ & 6.4 & 1 & 6.4 & 3.572 & 0.9561 \\
$\mathbf{X}_{\mathbf{1}}{ }^{2}$ & 36.07 & 1 & 36.07 & 20.13 & 0.0207 \\
$\mathbf{X}_{2}^{2}$ & 137.89 & 1 & 137.89 & 76.95 & 0.0031 \\
Residual & 5.38 & 3 & 1.79 & & \\
Corr. Total & 1714.21 & 8 & & & \\
\hline
\end{tabular}

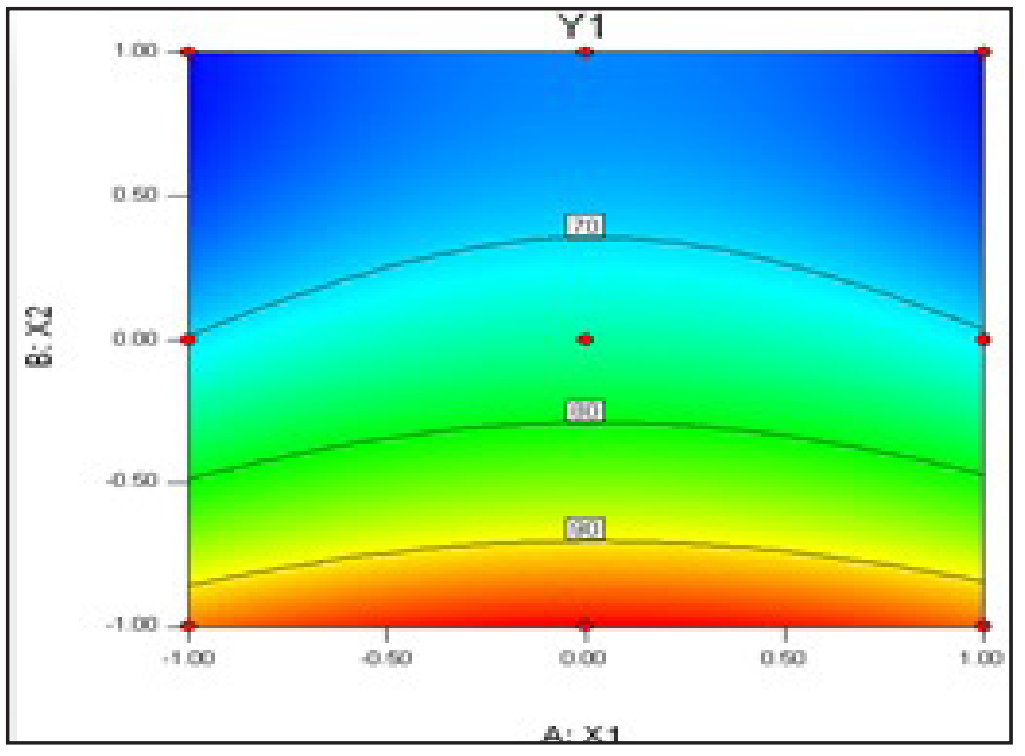

Figure 3: (a) Two dimensional contour plot; (b) three dimensional (3D) response surface plots for Y3 (\% Cumulative release) 


\section{Kinetic model}

The value of coefficient of regression for different models of formulation F1 to F9 is given in Table No. 7. The coefficient of regression value for the optimized batch F2 was found to be highest i.e. $\mathbf{0 . 9 9 5}$ for Zero order model and hence the release mechanism was found to follow zero order kinetic release model.

\section{Stability Studies}

Formulation showing optimum result was selected for stability studies. According to ICH guidelines ${ }^{18}$ selected formulation (F2) was stored at $40^{\circ} \mathrm{C}$ temperature and
$75 \%$ relative humidity $(\mathrm{RH})$ for a period of 3 months. Formulation was evaluated at periodical intervals of one month for $\%$ cumulative release, Floating lag time and Floating time. The drug content obtained after periodic intervals was found in the range of $98.21 \%$ to $98.05 \%$ and hence did not show any major differences. Floating lag time was also not affected by the stability conditions as shown in the Table 8 . Floating lag time was observed in the range of $27 \mathrm{sec}$ to $30 \mathrm{sec}$ Floating time was observed at $>12 \mathrm{hr}$ no major differences were observed. Evaluation parameters do not show any major difference and all are in accepted limits.

\begin{tabular}{|c|c|c|c|c|c|c|c|c|}
\hline \multirow[t]{2}{*}{ Sr. no. } & \multirow[t]{2}{*}{ Formu-lation } & \multirow[t]{2}{*}{ Zero Order } & \multirow[t]{2}{*}{ First Order } & \multirow[t]{2}{*}{ Higuchi Model } & \multirow[t]{2}{*}{ Hixon-Crowel } & \multicolumn{3}{|c|}{ Korsmeyer-Peppas } \\
\hline & & & & & & $\mathbf{R}^{2}$ & $\mathrm{~K}$ & $\mathbf{N}$ \\
\hline 1 & $\mathrm{~F} 1$ & 0.495 & 0.864 & 0.784 & 0.742 & 0.955 & 1.864 & 0.121 \\
\hline 2 & $\mathrm{~F} 2$ & 0.995 & 0.964 & 0.908 & 0.985 & 0.989 & 1.041 & 0.884 \\
\hline 3 & F3 & 0.902 & 0.965 & 0.980 & 0.950 & 0.963 & 1.394 & 0.417 \\
\hline 4 & $\mathrm{~F} 4$ & 0.473 & 0.923 & 0.772 & 0.764 & 0.861 & 1.903 & 0.119 \\
\hline 5 & F5 & 0.914 & 0.945 & 0.952 & 0.946 & 0.930 & 1.292 & 0.622 \\
\hline 6 & F6 & 0.919 & 0.938 & 0.953 & 0.937 & 0.952 & 1.236 & 0.668 \\
\hline 7 & $\mathrm{~F} 7$ & 0.966 & 0.939 & 0.959 & 0.941 & 0.945 & 1.419 & 0.572 \\
\hline 8 & F8 & 0.961 & 0.935 & 0.922 & 0.953 & 0.963 & 1.251 & 0.623 \\
\hline 9 & F9 & 0.976 & 0.970 & 0.951 & 0.978 & 0.974 & 1.111 & 0.718 \\
\hline
\end{tabular}

Table 8: Evaluation parameter of stability batch F2

\begin{tabular}{|c|c|c|c|}
\hline \multirow[t]{2}{*}{ Days } & \multirow[t]{2}{*}{ Drug (\%) } & \multicolumn{2}{|c|}{ Floating Behavior } \\
\hline & & FLT (Sec) & $\begin{array}{l}\text { Floating } \\
\text { duration (hrs) }\end{array}$ \\
\hline \multicolumn{4}{|c|}{ Before Storage } \\
\hline 0 day & $98.21 \pm 2.5$ & $27 \pm 5$ & $>12 \mathrm{hrs}$ \\
\hline \multicolumn{4}{|c|}{ After Storage } \\
\hline 7 days & $98.17 \pm 1.5$ & $27 \pm 9$ & $>12 \mathrm{hrs}$ \\
\hline 15 days & $98.15 \pm 1.5$ & $28 \pm 7$ & $>12$ hrs \\
\hline 30 days & $98.10 \pm 2.0$ & $29 \pm 6$ & $>12 \mathrm{hrs}$ \\
\hline 60 days & $98.10 \pm 2.5$ & $30 \pm 5$ & $>12 \mathrm{hrs}$ \\
\hline 90 days & $98.05 \pm 1.5$ & $30 \pm 6$ & $>12 \mathrm{hrs}$ \\
\hline
\end{tabular}




\section{Gamascintigraphy study}

Gamma scintigraphic is a technique whereby the transit of a dosage form through its intended site of delivery can be non-invasively imaged in vivo via the judicious introduction of an appropriate short lived gamma emitting radioisotope. The technique of Gamascintigraphy has become the most popular method to investigate the gastrointestinal performance of the product. ${ }^{11} \mathrm{Tc} 99 \mathrm{~m}$ is inexpensive and readily available through the use of portable generators. ${ }^{19} \mathrm{Tc}-99 \mathrm{~m}$ possesses most of the characteristics of an ideal radionuclide and hence found widespread applications in nuclear and in pharmaceutical formulation development.
In the present study in vivo gamma scintigraphic study was done to observe the in vivo floating behavior of optimized floating tablet. Radio labeled formulation was evaluated for its radiolabelling efficiency it was found more than $90 \%$. Therefore, $99 \mathrm{~m}$ Tc acts as the marker for locating the transit of the floating atenolol tablet. ${ }^{11}$ It was observed in the gamma images that optimized formulation (batch F2) was retained in the stomach more than 6 hours.A measurable number of counts of 99mTc-tagged atenolol formulation (F2) for the 6-hour Study period shown good gastro-retention (Shown in Figure 4).

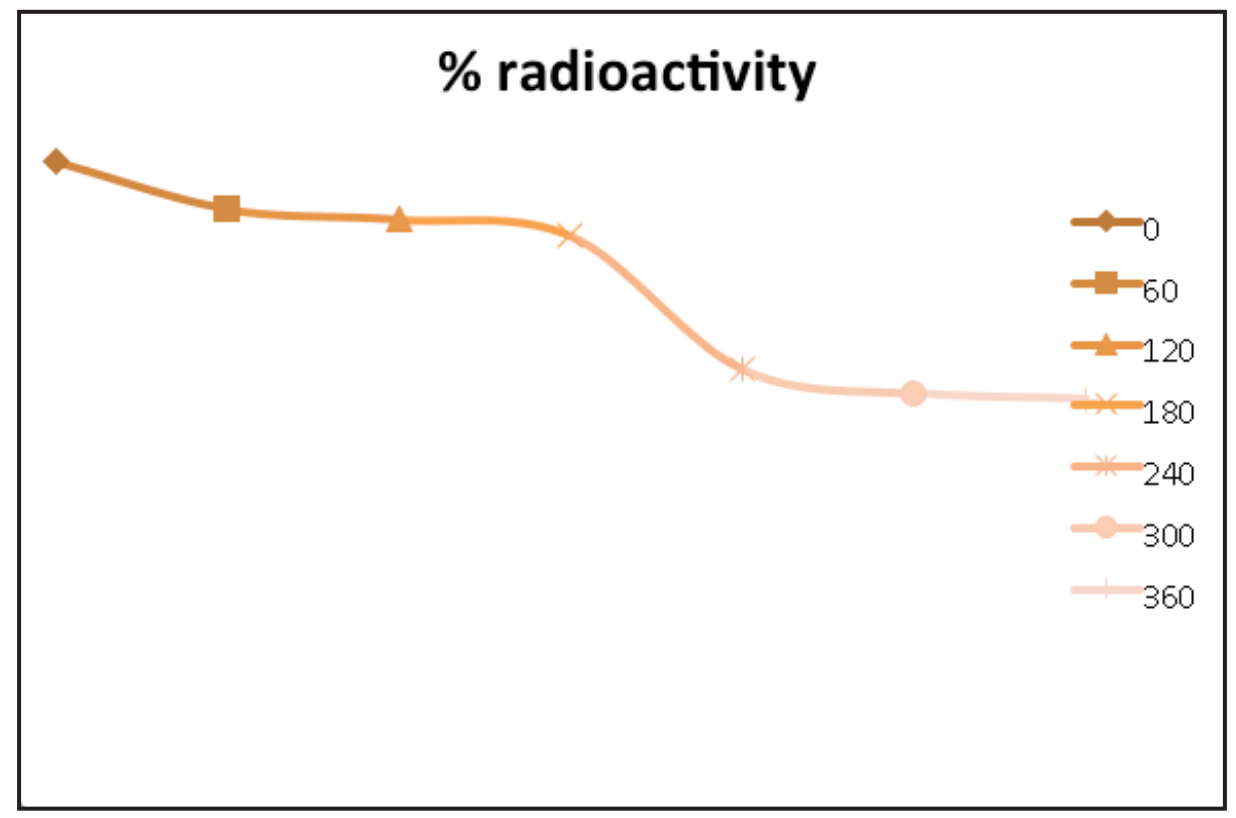

Figure 4: Representative Gastric emptying curve for the radio labeled formulation F2.

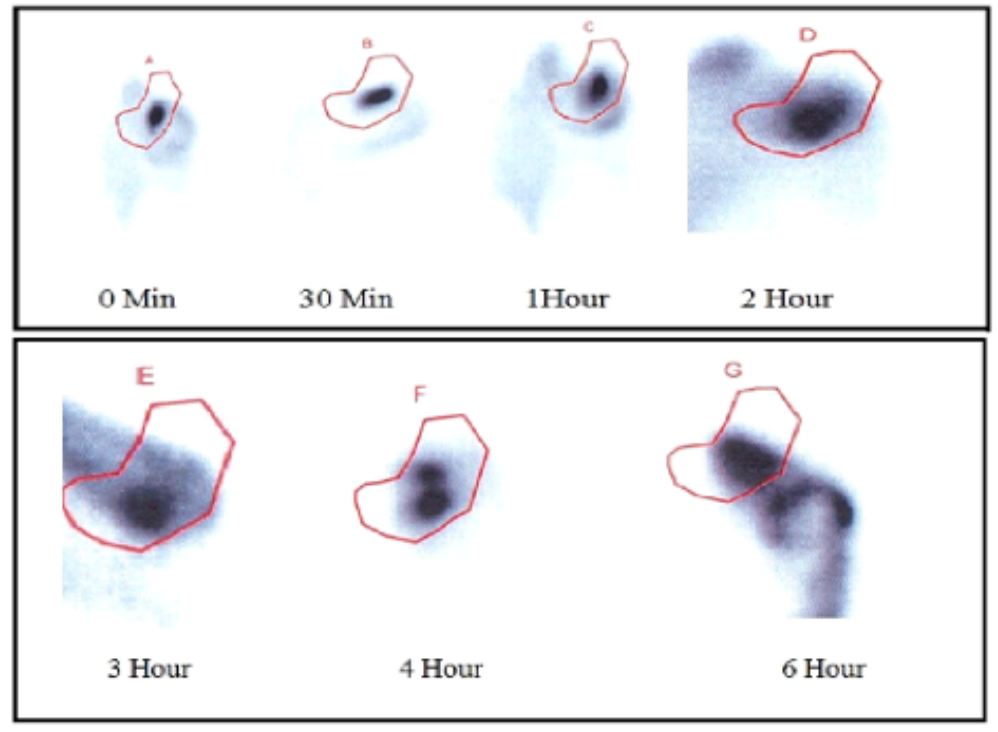

Figure 5: Representative gamma scintigraphic images of Floating matrix tablet in Rabbits 
A representative rabbit gamma scintigraphic image has been shown at 0,2 and $5 \mathrm{~h}$ in fig. 5. Gamma scintigraphic studies revealed the location of the capsule in 6 healthy rabbits. Posterior whole body images at various time intervals (15 minutes, 30 minutes, and 1, 2, 3, 4, and 5 hours) showed the retention of the tablet in the stomach for more than 5 hours, as shown in vitro studies.

\section{CONCLUSION}

Floating matrix tablet of atenolol containing combination of HPMC K4 M, LBG and sodium bicarbonate shown desired characteristics of floating formulation. The optimized formulation F2 follows the zero order kinetics model mechanism. In vitro buoyancy studies indicate that the formulation is suitable for gastro retention. This data was supported by performing Gamascintigraphy study on Rabbits; results indicate the prolongation of gastric residence time. This retention in the stomach can improve the absorption of Atenolol.

\section{ACKNOWLEDGEMENT}

Authors wish to thank STES's Sinhgad institute of pharmacy, narhe, Pune for providing facilities for completion of this project. Authors are thankful to Dr. (Mrs) Swati Pund (HOD Dept. of Quality Assurance) and Prof. Shalaka Dhat (HOD Dept. of Pharmaceutics) for their unconditional support during the completion of this work.

\section{CONFLICTS OF INTEREST}

Authors have no conflicts of interest.

\section{ABBREVIATION}

HPMC (Hydroxypropyl methyl cellulose), LBG (Locust bean gum), FLT (Floating lag time, FT (Floating time), $\mathrm{Tg}$ (glass transition temperature), ANOVA (Analysis of variance), $\mathrm{RH}$ (Relative humidity)

\section{REFERENCES}

1. Shuang $\mathrm{H}$, Feng Li. Formulation and evaluation of novel coated floating tablets of bergenin and cetirizine dihydrochloride for gastric delivery. Drug Dev Ind Pharm. 2012; 38(10): 1280-8.
2. Junting J, Chendong D, Wenli Z, Yanxia C, Jianping L. Evaluation of pharmacokinetic and pharmacodynamic relationship for oral sustainedrelease atenolol pellets in rats. J Pharm Biomed Anal. 2011; 55(2): 342-8.

3. Sastry S, Reddy I, Khan M. Atenolol gastrointestinal therapeutic system: optimization of formulation variables using response surface methodology. J Control Release. 1997; 45(2): 121-30.

4. Sang C, Jun S. Enhanced bioavailability of atenolol by transdermal administration of the ethylene-vinyl acetate matrix in rabbits. Eur J Pharm Biopharm. 2003; 56: 439-43.

5. Brahma N, Kwon H. Floating drug delivery systems: an approach to oral controlled drug delivery via gastric retention. J. Control. Release. 2000; 63(3): 235-59.

6. Yang L, Shah J, Fassihi R. A new intragastric delivery system for the treatment of Helicobacter pylori associated gastriculcer: in vitro evaluation. J. Control. Release. 1999; 57(3): 215-22.

7. Streubel A, SiepmannJ, Bodmeier R. Floating matrix tablets based on low density foam powder: effects of formulation and processing parameters on drug release. Eur J Pharm Sci. 2003; 18: 37-45.

8. Dorozynski P, Jachowicz R, Kulinowski P, Kwiecinski S, Szybinski K, Skorka $\mathrm{T}$, Jasinski A. The polymers for the preparation of hydrodynamically balanced systems - methods of evaluation. Drug DevInd Pharm. 2004; 30(9): 947-57.

9. Higuchi T. Mechanism of sustained action medication. J. Pharm. Sci. 1963; 52 : 1145-9.

10. Korsmeyer R, Gurny R, Docler E, Buri P, Peppas N. Mechanism of solute release from porous hydrophilic polymers. Int. J. Pharm. 1983; 15: 25-35.

11. Pund S, Joshi A, Vasu K, Nivsarkar M, Shishoo C . Gastroretentive delivery of rifampicin: In vitro mucoadhesion and in vivo gamma Scintigraphy. Int. J. Pharm 2011; 411: 106-112.

12. Jain S, Agrawal G, Jain N. Evaluation of Porous Carrier-based Floating Orlistat Microspheres for Gastric Delivery. AAPS Pharm Sci Tech. 2006; 7(4): E54-62.

13. Samaligy EI, Yahia M, Basalious S, Basalious E. Formulation and evaluation of diclofenac sodium buccoadhesive discs. Int J Pharm. 2004; 286: 27-39.

14. GuoJ, Skinner G, Harcum W, Barnum P. Pharmaceutical applications of naturally occurring water-soluble polymers. Pharm Sci Technolo Today. 1998; 1(6): 254-61.

15. Patel V, Prajapati B, Patel M. Formulation, evaluation and comparison of bilayered and multilayered mucoadhesive buccal devices of propranolol hydrochloride. AAPS Pharm Sci Tech. 2007; 8(1): E1-8.

16. Viridéna A, Wittgrenb B, Larsson A. Investigation of critical polymer properties for polymer release and swelling of HPMC matrix tablets. Eur. J. Pharm. Sci. 2009; 36 (2): 297-309.

17. Singh B, Kim K. Floating drug delivery systems: an approach to oral controlled drug delivery via gastric retention. J . control release. 2000; 63 : 235-59.

18. Mathews BR. Regulatory aspects of stability testing in Europe. Drug Devlnd Pharm. 1999; 25(7): 831-56.

19. Wilding I, Coupe A, Davis S. The role of scintigraphy in oral drug delivery. Adv. Drug Deliv. Rev. 2001; 46: 103-24. 